\section{Literature Cited}

1) Fort, R. J. and W. R. Moore: Trans. Faraday Soc., 62, 1112 (1966).

2) Hammond, L. W., K. S. Howard and R. A. McAllister: $J$. Phys. Chem., 62, 637 (1958).

3) Heric, E. L. and J. G. Brewer: J. Chem. Eng. Data, 12, 574 (1967).

4) Heric, E. L. and J. G. Brewer: ibid., 14, 55 (1969).

5) Kalidas, R. and G. S. Laddha: ibid., 9, 142 (1964).

6) Katti, P. K. and M. M. Chaudhri: ibid., 9, 442 (1964).
7) Kikuchi, M. and E. Oikawa: Nippon Kagaku Zasshi, 88, 1259 (1967).

8) Morisue, T. K. Noda and K. Ishida: J. Chem. Eng. Japan, 5, 219 (1972).

9) Mussche, M. J. and L. A. Verhoeye: J. Chem. Eng. Data, 20, 46 (1975).

(Presented at the Tohoku Meeting of The Soc. of Chem. Engrs., Japan, at Yonezawa, July 26, 1976.)

\title{
VAPOR-LIQUID EQUILIBRIUM DATA FOR THE SYSTEMS ALLYL ALCOHOL-ETHYLBENZENE AND ALLYL ALCOHOL-p-XYLENE
}

\author{
BHUSHAN KUMAR AND K. S. N. RAJU \\ Department of Chemical Engineering and Technology Panjab University, \\ Chandigarh-160014, India
}

\section{Introduction}

With a view to utilizing alcohols as entraining agents for the separation of close-boiling hydrocarbons, isobaric vapor-liquid equilibrium data for the systems allyl alcohol-ethylbenzene and allyl alcohol-p-xylene were obtained at $760 \pm 2 \mathrm{mmHg}$ pressure. The system allyl alcohol-ethylbenzene, having a boiling range of $39.3^{\circ} \mathrm{C}$, forms a constant-boiling mixture at $96.9^{\circ} \mathrm{C}$, which is the normal boiling point of allyl alcohol. The vapor and liquid composition curves merge with each other at concentrations of allyl alcohol above 90 mole $\%$. The system allyl alcohol- $p$-xylene, having a boiling range of $41.5^{\circ} \mathrm{C}$, forms a constant-boiling mixture at $96.9^{\circ} \mathrm{C}$ and at concentrations above 93 mole $\%$.

\section{Experimental Procedure}

Preliminary drying of allyl alcohol obtained from Riedel was done by refluxing for four hours with chemically pure potassium carbonate and was finally purified by distillation in a well-insulated glass column. The method of purification of ethylbenzene and $p$-xylene along with the details of the experimental set-up for obtaining vapor-liquid equilibrium data are described elsewhere ${ }^{2)}$. The physical properties of the pure compounds are listed in Table 1.

Received May 23, 1977. Correspondence concerning this article should be addressed to K. S. N. Raju.

\section{Results and Discussion}

The activity coefficients were calculated using Eqs. (1) and (2):

$$
\begin{aligned}
& \gamma_{1}=\frac{\pi y_{1}}{P_{1}^{0} x_{1}} \exp \left[\frac{\left(\pi-P_{1}^{0}\right)\left(B_{11}-V_{1}\right)}{R T}+\frac{\pi \delta_{12} y_{2}^{2}}{R T}\right] \\
& \gamma_{2}=\frac{\pi y_{2}}{P_{2}^{0} x_{2}} \exp \left[\frac{\left(\pi-P_{2}^{0}\right)\left(B_{22}-V_{2}\right)}{R T}+\begin{array}{c}
\pi \delta_{12} y_{1}^{2} \\
R T
\end{array}\right]
\end{aligned}
$$

where

$$
\delta_{12}=2 B_{12}-B_{11}-B_{22}
$$

Table 2 gives the vapor-liquid equilibrium data for these systems. The correlations used for the estimation of pure component properties of ethylbenzene and $p$-xylene have been described earlier ${ }^{21}$. Based on the recommendations given elsewhere ${ }^{1,8)}$, the vapor pressures, second virial coefficients and liquid molar volumes of allyl alcohol were estimated by the correlations of Thek-Stiel ${ }^{13}$, O'Connell-Prausnit ${ }^{11 \text { ' }}$ and modified Goldhammer ${ }^{5)}$, respectively. The cross virial coefficients $B_{12}$ were evaluated by employing the mixing rules described by O'Connell and Prausnitz ${ }^{11}$. The data for both these systems were found to be thermodynamically consistent by application of the tests of Herington ${ }^{6)}$, Norrish-Twigg ${ }^{10)}$ and Black $^{31}$. The function (D-J) in the Herington test for the systems allyl alcohol-ethylbenzene and allyl alcohol$p$-xylene was found to be -12.92 and -11.91 , respectively. The activity coefficient-composition plot as shown in Figs. $\mathbf{1}$ and $\mathbf{2}$ for these systems indicate maxima-minima below compositions of about 10 


\begin{tabular}{|c|c|c|c|c|}
\hline \multicolumn{2}{|c|}{ Table 1} & \multicolumn{3}{|c|}{ Physical properties of materials } \\
\hline \multicolumn{2}{|l|}{ Material } & Bp. $\left[{ }^{\circ} \mathrm{C}\right]$ & \multicolumn{2}{|c|}{$\begin{array}{l}\text { Refractive index } \\
\text { at } 30^{\circ} \mathrm{C}\end{array}$} \\
\hline \multicolumn{2}{|l|}{ allyl alcohol } & $\begin{array}{l}96.9 \\
96.9(4)\end{array}$ & \multicolumn{2}{|c|}{1.4088} \\
\hline \multicolumn{2}{|l|}{ ethylbenzene } & $\begin{array}{l}136.2 \\
136.19(15)\end{array}$ & \multicolumn{2}{|c|}{$\begin{array}{l}1.4908 \\
1.4905(14)\end{array}$} \\
\hline \multicolumn{2}{|l|}{$p$-xylene } & $\begin{array}{l}138.5 \\
138.4(7)\end{array}$ & \multicolumn{2}{|c|}{$\begin{array}{l}1.4908 \\
1.4905(14)\end{array}$} \\
\hline \multicolumn{5}{|c|}{ Table 2 Vapor-liquid equilibrium data } \\
\hline$t\left[{ }^{\circ} \mathrm{C}\right]$ & $x_{1}$ & $y_{1}$ & $\gamma_{1}$ & $\gamma_{2}$ \\
\hline \multicolumn{5}{|c|}{ System allyl alcohol (1)-ethylbenzene (2) } \\
\hline 96.9 & 0.965 & 0.966 & 0.998 & 3.133 \\
\hline 96.9 & 0.935 & 0.936 & 1.000 & 3.177 \\
\hline 96.9 & 0.871 & 0.888 & 1.019 & 2.799 \\
\hline 96.9 & 0.886 & 0.894 & 1.007 & 2.995 \\
\hline 97.2 & 0.796 & 0.844 & 1.050 & 2.440 \\
\hline 97.7 & 0.712 & 0.811 & 1.109 & 2.058 \\
\hline 98.2 & 0.647 & 0.794 & 1.172 & 1.796 \\
\hline 99.1 & 0.546 & 0.772 & 1.310 & 1.498 \\
\hline 100.0 & 0.454 & 0.753 & 1.489 & 1.310 \\
\hline 100.8 & 0.409 & 0.753 & 1.611 & 1.182 \\
\hline 102.6 & 0.323 & 0.723 & 1.843 & 1.090 \\
\hline 104.1 & 0.263 & 0.688 & 2.049 & 1.074 \\
\hline 106.8 & 0.185 & 0.656 & 2.538 & 0.981 \\
\hline 109.3 & 0.150 & 0.618 & 2.726 & 0.968 \\
\hline 111.8 & 0.123 & 0.586 & 2.907 & 0.940 \\
\hline 114.5 & 0.100 & 0.496 & 2.796 & 1.025 \\
\hline \multicolumn{5}{|c|}{ System allyl alcohol (1)-p-xylene (2) } \\
\hline 96.9 & 0.967 & 0.968 & 0.996 & 3.253 \\
\hline 96.9 & 0.942 & 0.942 & 0.997 & 3.358 \\
\hline 96.9 & 0.870 & 0.891 & 1.022 & 2.814 \\
\hline 97.2 & 0.800 & 0.855 & 1.060 & 2.414 \\
\hline 97.8 & 0.716 & 0.828 & 1.122 & 1.974 \\
\hline 98.4 & 0.651 & 0.818 & 1.194 & 1.671 \\
\hline 99.3 & 0.552 & 0.790 & 1.316 & 1.455 \\
\hline 100.2 & 0.472 & 0.773 & 1.461 & 1.292 \\
\hline 101.5 & 0.398 & 0.766 & 1.647 & 1.119 \\
\hline 103.3 & 0.316 & 0.742 & 1.888 & 1.023 \\
\hline 105.6 & 0.245 & 0.714 & 2.174 & 0.959 \\
\hline 108.8 & 0.182 & 0.666 & 2.461 & 0.934 \\
\hline 111.3 & 0.138 & 0.648 & 2.907 & 0.865 \\
\hline 113.8 & 0.114 & 0.602 & 3.045 & 0.882 \\
\hline 116.0 & 0.098 & 0.556 & 3.054 & 0.906 \\
\hline 120.5 & 0.067 & 0.413 & 2.889 & 1.016 \\
\hline 121.0 & 0.066 & 0.416 & 2.916 & 0.998 \\
\hline
\end{tabular}

mole \% allyl alcohol. As shown in Table 3, the correlations of Wilson $^{16)}$ and $\mathrm{NRTL}^{12)}$ fit the activity coefficient-composition data quite satisfactorily above 0.1 mole fraction of allyl alcohol. The constants in these correlations were evaluated by using the nonlinear least squares technique described by Nagahama et al. ${ }^{91}$ minimizing $\ln \left(\gamma_{1} / \gamma_{2}\right)$ function. The value of the nonrandom constant, $\alpha_{12}$, in the NRTL correlation was taken to be 0.47 .

\section{Conclusions}

Vapor-liquid equilibrium data for allyl alcoholethylbenzene and allyl alcohol-p-xylene systems were obtained at $760 \mathrm{mmHg}$ pressure. Both these systems formed constant-boiling mixtures at $96.9^{\circ} \mathrm{C}$ and at all concentrations of allyl alcohol above about 90 mole $\%$. The data are thermodynamically consistent. The ac-

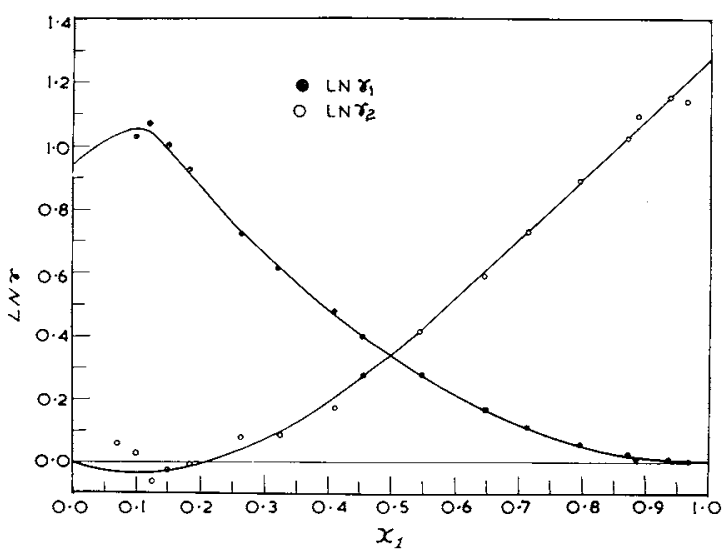

Fig. 1 Activity coefficient-composition diagram for allyl alcohol-ethylbenzene system

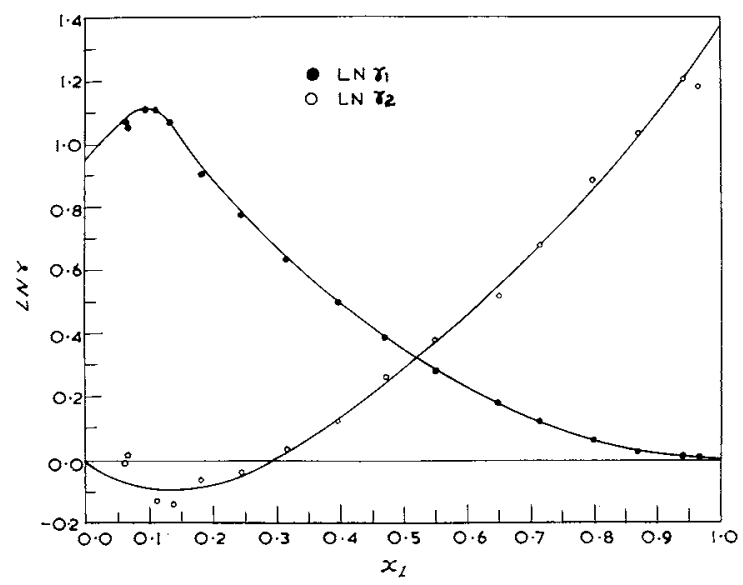

Fig. 2 Activity coefficient-composition diagram for allyI alcohol-p-xylene system

Table 3 Data fit in Wilson and NRTL correlations Wilson

NRTL

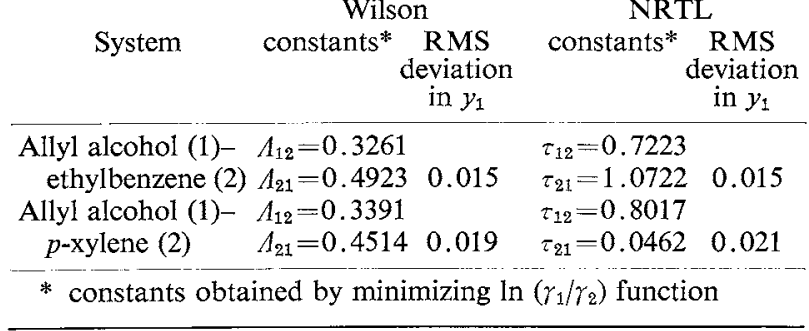

tivity coefficient-composition plots give maximaminima formation in the dilute allyl alcohol concentration region. The correlations of Wilson and NRTL fit the data well.

\section{Nomenclature}

$\begin{array}{llr}B & =\text { second virial coefficient } & {\left[\mathrm{cm}^{3} / \mathrm{mole}\right]} \\ B_{12} & =\text { cross virial coefficient } & {\left[\mathrm{cm}^{3} / \mathrm{mole}\right]} \\ P^{\circ} & =\text { vapor pressure of pure component } & {[\mathrm{mmHg}]} \\ R & =\text { gas constant } & {\left[\mathrm{cal} / \mathrm{mol} \cdot{ }^{\circ} \mathrm{K}\right]} \\ T & =\text { absolute temperature } & {\left[{ }^{\circ} \mathrm{K}\right]} \\ t & =\text { temperature } & {\left[{ }^{\circ} \mathrm{C}\right]} \\ V & =\text { molar volume of pure component in } & \\ & & \text { liquid phase } \\ x & =\text { mole fraction in liquid phase } & {\left[\mathrm{cm}^{3} / \mathrm{mole}\right]} \\ y & =\text { mole fraction in vapor phase } & {[-]}\end{array}$




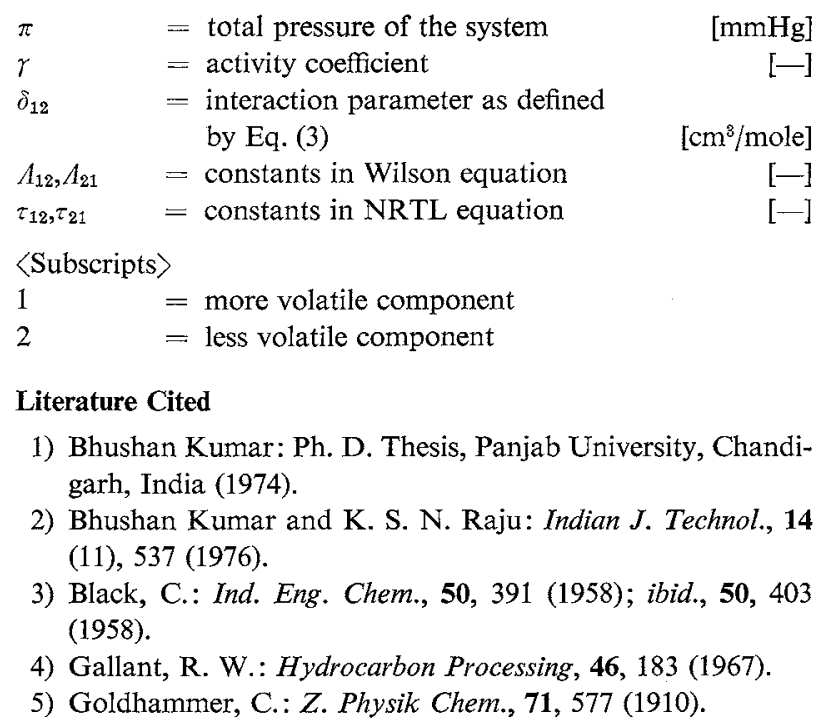

6) Herington, E. F. G.: I. Inst. Petrol., 37, 457 (1951).

7) Lange, N. A. Ed.: "Handbook of Chemistry", 10th ed., McGraw-Hill, New York (1967).

8) Mittal, S.: M. Sc. Chem. Engg. Thesis, Panjab University, Chandigarh, India (1973).

9) Nagahama, K., I. Suzuki and M. Hirata: J. Chem. Eng. Japan, 4, 1 (1971).

10) Norrish, R. S. and G. H. Twigg: Ind. 'Eng. Chem., 46, 201 (1954).

11) O'Connell, J. P. and J. M. Prausnitz: Ind. Eng. Chem., Process Des. Dev., 6, 245 (1967).

12) Renon, H. and J. M. Prausnitz: AIChE J., 14, 135 (1968).

13) Thek, R. E. and L. I. Stiel: ibid., 12, 599 (1966); ibid., 13, 626 (1967).

14) Timmermans, J.: "Physico-Chemical Constants of Pure Organic Compounds", Vol. II, Elsevier, Amsterdam (1965).

15) Weast, R. C. Ed.: "Handbook of Chemistry and Physics", 50th ed., The Chemical Rubber Co. (1969/70).

16) Wilson, G. M.: J. Am. Chem. Soc., 86, 127 (1964).

\title{
APPLICATION OF THE PERTURBATION THEORY TO VAPOR-LIQUID EQUILIBRIA OF SYSTEMS CONTAINING A POLAR SUBSTANCE
}

\author{
Hirokatsu MASUOKA, Chiaki YOKOYAMA, Yasuhiko ARAI and Shozaburo SAITO \\ Department of Chemical Engineering, Tohoku University, Sendai 980
}

In a previous paper ${ }^{4}$, it was shown that the perturbation theory of Barker-Henderson in conjunction with the conformal solution theory proposed by Mansoori and Leland ${ }^{3}$ is applicable to the correlation of vapor-liquid equilibria of systems containing ammonia. In the present study, the perturbation theory has been further applied to systems containing a polar substance other than ammonia. The vaporliquid equilibria of the binary system consisting of a nonpolar substance and a polar substance (acetone, ethyl ether, methyl ethyl ketone or methyl acetate) were calculated by the same procedure as reported previously.

The pair-potential energy-function used is the Lennard-Jones (12-6) type, described in the previous paper:

$$
u(r)=4 \varepsilon\left[\left(\frac{\sigma}{r}\right)^{12}-\left(\frac{\sigma}{r}\right)^{6}\right]
$$

where $\varepsilon$ and $\sigma$ are temperature-dependent potential parameters and are defined as follows:

Received June 2, 1977. Correspondence concerning this article should be addressed to S. Saito. Y. Arai is now at Dept. of Chem. Eng., Kyushu Univ., Fukuoka 812.

$$
\begin{gathered}
\varepsilon=\varepsilon^{\circ} \mathscr{F}^{2} \\
\sigma=\sigma^{\circ} \mathscr{F}^{-1 / 6} \\
\mathscr{F}=1+7 Q^{4} / 20 k T \varepsilon^{\circ}\left(\sigma^{\circ}\right)^{10}+3 Q^{2} \alpha / 4 \varepsilon^{\circ}\left(\sigma^{\circ}\right)^{8}: \\
\text { for nonpolar substance } \\
\mathscr{F}=1+\mu^{4} / 12 k T \varepsilon^{\circ}\left(\sigma^{\circ}\right)^{6}+\mu^{2} \alpha / 2 \varepsilon^{\circ}\left(\sigma^{\circ}\right)^{6}: \\
\text { for polar substance }
\end{gathered}
$$

where $\alpha, \boldsymbol{\mu}$ and $\boldsymbol{Q}$ are polarizability, dipole moment, and quadrupole moment, respectively. These parameters were determined by using vapor pressure data and saturated $P-V-T$ relation for pure substances ${ }^{1,7)}$. The values of these parameters for nonpolar substances are given in Table $\mathbf{1}$, where $\alpha$ is arbitrarily assumed to be zero. Figure 1 shows the vapor pressures and saturated volumes for methane calculated with two different sets of parameters. The pairpotential energy function containing the quadrupole moment seems to improve the calculated results. As shown in Fig. 2, the following linear relations were obtained between the reduced potential parameters and the acentric factor:

$$
\varepsilon^{\circ} / k T_{c}=0.734-0.396 \omega
$$

